\title{
$\underline{\text { Interaction between local magma ocean evolution and mantle dynamics on Mars }}$
}

C.C. Reese, V.S. Solomatov and C.P. Orth, Department of Earth and Planetary Sciences Washington University, St. Louis, MO 63130

\begin{abstract}
Large scale features of Mars' crustal structure including the hemispherical dichotomy and Tharsis were established very early in planetary history. Geodynamical models for origin of the dichotomy and Tharsis, such as lithospheric recycling and a plume from the core mantle boundary, respectively, involve solid state mantle flow and are difficult to reconcile with timing constraints. An alternative point of view is that the martian crustal asymmetry and Tharsis can be associated with the upwelling and spreading of large, impact induced, melt regions, i.e., local magma oceans.

While the local magma ocean induced upwelling model satisfies timing constraints on dichotomy and Tharsis formation, it neglects any interaction with longer timescale mantle dynamics and cannot explain recent volcanic activity at Tharsis. In this study, fully three-dimensional, spherical shell simulations are utilized to investigate coupling between local magma oceans and mantle dynamics with radiogenic heating and core heat flow. For low core heat flux, it is found that upwellings driven by local magma ocean buoyancy are transient features of planetary evolution which is dominated by sublithospheric instabilities. With increasing core heat flux, local magma ocean induced upwellings strongly influence the pattern of thermal plumes from the core mantle boundary which can remain stable for $\sim 4.5$ Gyr. Predicted melt volumes, present day melting rate, and crustal structure are compared to observational constraints.
\end{abstract}




\section{INTRODUCTION}

Geological and geochemical observations indicate rapid development of large scale crustal structure early in Martian history. Both the hemispherical crustal dichotomy (Zuber, 2001; Frey et al., 2002; Nimmo and Tanaka, 2005) and Tharsis province (Banerdt and Golombek, 2000; Phillips et al., 2001; Johnson and Phillips, 2005; Solomon et al., 2005) were emplaced during the Noachian epoch (Table 2), i.e., within $\sim 1$ Gyr of planet formation. Geochemical analyses of Martian meteorites are also consistent with early silicate differentiation (Harper, 1995; Lee and Halliday, 1997; McLennan, 2001).

The Martian crustal hemispherical dichotomy is expressed topographically as a north to south slope of $\sim 0.036^{\circ}$ such that the south pole is $\sim 6 \mathrm{~km}$ higher than the north pole (Smith et al., 1999) with a complex boundary zone (Frey et al., 1998) and geologically as a contrast between heavily cratered southern highlands and smoother northern lowlands. The size-frequency distribution of circular depressions in the resurfaced northern plains is similar to the crater distribution in the south implying that southern basement crust is of approximately the same age as northern crust, i.e. early Noachian (Frey et al., 2002), consistent with geochemical constraints on differentiation. Mars crustal structure is constrained by topography and gravity data (Smith et al., 2001; Lemoine et al., 2001) from Mars Global Surveyor (MGS). Models with uniform crustal density and varying crustal thickness (Zuber et al., 2000; Zuber, 2001, Neumann et al., 2004) consistent with the data predict a lower bound on the mean crustal thickness of $\sim 50 \mathrm{~km}$ and a general crustal thinning trend from south to north. The crustal structure in the dichotomy boundary zone is complex exhibiting a smooth transition in Arabia Terra but more scarplike regional offsets elsewhere.

Several hypotheses have been suggested for hemispherical dichotomy formation. Excavation by one or more large impacts (Wilhelms and Squyres, 1984; Frey and Schultz, 1988) is inconsistent 
with the lack of correlation between crustal structure and the boundary surface expression, noncircular shape and complex boundary topography, and lack of filled basin gravity signatures such as Utopia for the northern lowlands as a whole (Zuber et al., 2000; Zuber, 2001). The late stages of a transient episode of plate tectonics has been suggested (Sleep, 1994) although subduction of $35 \mathrm{~km}$ thick crust (mean lowland thickness) may be difficult due to the deeper basalt-eclogite transition on Mars. Long wavelength (spherical harmonic degree 1) mantle convection is possible for Mars but requires a layered viscosity structure (Zhong and Zuber, 2001). Such a convective planform could produce a dichotomy by enhanced melting and crustal production at the upwelling or crustal erosion by the downwelling. Timescales for surface recycling or mantle flow are difficult to reconcile with early formation of the dichotomy (Solomon et al., 2005) and preservation of Utopia crustal structure makes northern crustal thinning unlikely (Neumann et al., 2004). Gravitational instability due to crystallization of a global magma ocean can lead to mantle overturn that may have a strong degree 1 component and might provide a mechanism for dichotomy formation (Hess and Parmentier, 2001; Elkins-Tanton et al., 2005a;b).

Later in the Noachian, magmatism and tectonism were focused at Tharsis province, a broad topographic rise comprised of regional centers of volcanism and deformation (e.g., Anderson et al., 2001). Large crustal structure variations (Zuber et al., 2000) and layered volcanics in Valles Marineris (McEwen et al., 1999) support the notion of constructional magmatism as the primary contributor to Tharsis elevation (Solomon and Head, 1982). Localized magmatism resulted in a lithospheric load with an estimated volume of $\sim 3 \times 10^{8} \mathrm{~km}^{3}$ (Phillips et al., 2001). Faulting patterns dating to the late Noachian are consistent with a flexural loading model based on present-day topography and gravity suggesting that the load was emplaced by that time (Banerdt and Golombek, 2000). Volcanism at Tharsis continued throughout Martian history but at much 
lower levels (Hartmann and Neukum, 2001). Tharsis formation probably postdates development of the hemispherical crustal dichotomy. Crustal thickening is superimposed on the global south to north trend (Zuber et al, 2000; Zuber, 2001, Neumann et al., 2004) and Tharsis volcanic units are emplaced on older magnetized crust (Johnson and Phillips, 2005).

Hypotheses for Tharsis formation have focused on a planform of mantle convection dominated by a single thermal plume as an explanation of the monopolar magmatic and tectonic activity. Deep mantle mineralogical phase changes are capable of stabilizing a one-plume pattern of convection (Weinstein, 1995; Harder and Christensen, 1996; Breuer et al., 1998; Spohn et al., 1998; Harder, 2000) but no plume model has reproduced Tharsis development on a timescale consistent with observation. Alternatively, if the Martian mantle is layered and thick southern crust acts as an insulating layer, hot plumes can develop beneath the insulating layer (Wenzel et al., 2004) although this hypothesis doesn't account for Tharsis' location near the dichotomy boundary. The spatial correlation of the Tharsis rise and dichotomy boundary motivates the hypothesis of edge driven convection as mechanism for Tharsis formation (King and Redmond, 2005). This hypothesis requires a deep, cold, stable, layer beneath southern hemisphere crust in order to initiate small scale convection and if edge driven convection occurs, it should be prevalent everywhere along the dichotomy boundary rather than focused at Tharsis.

An alternative possibility is that planetary formation processes and initial thermal and compositional conditions play an important role. Large impacts occurring during late stage accretion (e.g., Agnor et al., 1999) can produce localized, intact melt regions (Tonks and Melosh, 1992; 1993), i.e. local magma oceans. A local magma ocean evolves to a uniform global layer, i.e. a global magma ocean, only if buoyant melt is rapidly redistributed prior to any significant solidification (Tonks and Melosh, 1992;1993). A simple fluid dynamical model for local magma 
ocean evolution (Reese and Solomatov, 2006) suggests that if cooling and crystallization are fast compared to melt redistribution, the driving force for isostatic adjustment diminishes, melt region viscosity increases significantly, and restoration of a globally symmetric, fully molten layer can be difficult. Instead, a localized, mantle upwelling develops in response to the buoyant, partially molten local magma ocean. Preliminary studies of this mechanism have produced results which are in qualitative agreement with early crustal structure and timing constraints for dichotomy and Tharsis formation (Reese et al., 2004; Reese and Solomatov, 2006). However, both studies failed to address interaction between local magma ocean induced upwellings and longer timescale mantle dynamics. The study of Reese et al., (2004) was designed to isolate local magma ocean upwelling effects and neglected radiogenic mantle heating and core heat flow which are crucial for continued melting throughout planetary history (Hartmann and Neukum, 2001; Neukum et al., 2004). Reese and Solomatov, (2006) did not consider local magma ocean - mantle convection interaction at all.

In this paper, coupling of local magma ocean evolution and mantle dynamics with internal heating and core heat flux are investigated. The study is organized as follows. The fluid dynamical model for the evolution of a local magma ocean and hypothesis for origin of the dichotomy and Tharsis (Reese and Solomatov, 2006) is reviewed. The effects of local magma ocean evolution on Martian mantle convection and magmatic evolution are explored using fully three dimensional, spherical shell geometry simulations. Results are compared with observational constraints and future work is suggested.

\section{LOCAL MAGMA OCEAN EVOLUTION}

The intact melt region generated by a large impact can form a global magma ocean only if the ratio of the isostatic adjustment time to the melt cooling time is small (Tonks and Melosh, 1992; 1993). Convection in the local magma ocean and the radiative boundary condition at the surface 
control the crystallization time. Complete isostatic adjustment involves both radial relaxation as the buoyant melt region moves upward and a lateral component as melt is redistributed around the planet to a spherically symmetric state. In this section a model for local magma ocean evolution is reviewed (Reese and Solomatov, 2006).

\section{Formation of an impact induced local magma ocean}

The thermal state of proto-Mars prior to large impacts is not well constrained. A study which incorporates an improved planetesimal size distribution (but which neglects planetesimal heating due to decay of short lived radioisotopes) suggests that the interior can avoid widespread and deep melting during early accretion (Senshu et al., 2002). Mars could be a remnant, planetary embryo from from the runaway growth stage of planet formation (Chambers and Whetherill, 1998; Chambers 2004). After runaway growth, the planetesimal mass spectrum is characterized by Mars mass embryos separated by a factor of $\sim 10$ from a continuous power law distribution (Kokubo and Ida 1996; 1998; 2000). Impacting bodies with masses $\sim 0.1-1$ times the lunar mass seem likely. Large impacts are sufficiently energetic to produce melting and generate a localized magma ocean.

High velocity impacts generate a spherical shock wave which propagates into the target. Near the impact site, there is an isobaric core where shock pressures are approximately uniform. Outside the isobaric core, shock pressures decay with distance. For a hemispherical model of the shock pressure distribution (Fig. 1), vertical incidence, target to projectile density ratio of 1, and pressure drop off outside the isobaric core varying like $r^{-2}$, the radius of the region shocked to pressure $P$ (Tonks and Melosh, 1992;1993)

$$
r=2^{1 / 3}\left(\frac{v_{i}}{v_{i}^{m}}\right)^{1 / 2} a
$$


where $a$ is the impactor radius, $v_{i}$ is the impact velocity, and

$$
v_{i}^{m}=\frac{C}{S}\left[\left(1+\frac{4 S P}{\rho C^{2}}\right)^{1 / 2}-1\right],
$$

Implicit in this expression is the assumption of a linear shock velocity-particle velocity relationship (Melosh, 1989),

$$
U=C+S u_{p}
$$

where $U$ is the shock velocity and $u_{p}$ is the particle velocity. For dunite at shock pressures $P \geq 73$ $\mathrm{GPa}, C=4.4 \mathrm{~km} / \mathrm{s}$ and $S=1.5$ (Kieffer, 1977). Oblique impacts complicate this simple geometry, concentrating more energy downrange (Pierazzo and Melosh, 2000). The shock pressure corresponding to complete melting of solidus dunite is $P=115 \mathrm{GPa}$ (Tonks and Melosh, 1993). The radius of a region shocked to a melt fraction $\phi$ can be calculated from the near solidus Hugoniot in pressure-entropy space (Tonks and Melosh, 1993) and the relationship between melt fraction and entropy. The critical melt fraction $\phi_{c r} \sim 0.4$ corresponds to a rheological transition from low viscosity liquid to high viscosity partially molten solid (Solomatov, 2000). For linear melt fraction dependence on entropy, this corresponds to a shock pressure of $\sim 70 \mathrm{GPa}$. For an impact velocity of $v_{i} \sim 7 \mathrm{~km} / \mathrm{s}$, the radius of the region shocked to $\phi_{\mathrm{cr}}$

$$
R \approx 1.7 a
$$

The volume of the region with $\phi \geq \phi_{\text {cr }}$

$$
V=\frac{2}{3} \pi R^{3}\left(1-3 / 8 \frac{R}{R_{p}}\right)
$$

where $R_{p}$ is the planet radius and the term in parentheses corresponds to a geometrical correction giving the volume between the spherical surface radius $R_{p}$ and a hemisphere of radius $R$ centered on the surface (Tonks and Melosh, 1992). 
While some of the melt produced by a large impact gets redistributed about the planet by the excavation flow, sufficiently large impacts generate melt deep in a planet where it remains subsequent to crater excavation. The transient crater radius is given by the $\pi$-scaling law for the gravity regime (Schmidt and Housen, 1987),

$$
r_{c}=\frac{1}{2}\left(\frac{4}{3} \pi\right)^{1 / 3} C_{D}\left(3.22 \frac{g}{v_{i}^{2}}\right)^{-\beta} a^{1-\beta}
$$

where $C_{D}=1.6$ and $\beta=0.22$ are empirical scaling parameters (Melosh, 1989). For an impact velocity $v_{i} \sim 7 \mathrm{~km} / \mathrm{s}$,

$$
r_{c} \approx 300 \mathrm{~km}\left(\frac{a}{100 \mathrm{~km}}\right)^{0.78}
$$

The scaling laws $R \sim a$ and $r_{c} \sim a^{0.78}$ imply that as impactor size increases, the melt region radius increases faster than the crater radius. Thus, the retained melt fraction increases with increasing $a$ and eventually a large volume of melt can be retained (Fig. 2).

While an exact criterion for local magma ocean formation is not easily defined, Tonks and Melosh, (1992) suggest equal melt and transient crater volume. Assuming a parabolic cross section (Melosh, 1989) gives the crater volume $V_{c}=\gamma_{c} / 2 \pi r_{c}^{3}$ where the typical depth to radius ratio $\gamma_{c} \approx 1 / 2-2 / 3$. Equating volumes $V$ and $V_{c}$ gives the critical impactor radius for local magma ocean formation $a_{\mathrm{cr}} \approx 700-1500 \mathrm{~km}$. Such impactor size can be expected based on improved models of planetary formation (e.g., Agnor et al., 1999). The lower bound of this range corresponds to a local magma ocean size $R \sim 1000 \mathrm{~km}$. Magma pond forming impacts are significantly larger and more energetic than basin forming impacts (Fig. 2).

\section{Local magma ocean crystallization timescale}

For ultramafic silicates at low pressure and large melt fraction, the viscosity $\eta_{l} \sim 0.1 \mathrm{~Pa} \mathrm{~s}$ (Bottinga and Weill, 1972; Shaw, 1972; Persikov et al., 1990; Bottinga et al., 1995). At near 
liquidus conditions, komatiite viscosities range from 0.1 - $10 \mathrm{~Pa}$ s depending on $\mathrm{MgO}$ content (Huppert and Sparks, 1985). For low viscosity liquids, a power law governs viscosity variations with temperature (Bottinga et al., 1995) implying a minor effect over the melting range. Variations due to pressure are also small for a completely depolymerized melt (Andrade, 1952; Gans, 1972). The most significant rheological variation occurs at the critical melt fraction $\phi_{\mathrm{cr}}$ where the viscosity increases to a value near that of partially molten solids (e.g. Solomatov and Stevenson, 1993a). Thus, the viscosity of the magma ocean between $\phi=1$ and $\phi=\phi_{\mathrm{cr}}$ is assumed to be $\eta_{l} \sim 0.1 \mathrm{~Pa}$ s with an uncertainty factor of $\sim 10$.

Vigorous convection in the low viscosity melt region is the primary mode of cooling and crystallization. As the region cools, a partially solid layer develops at the bottom (Fig. 3). The magma ocean heat flux is determined by convection in the magma and the radiative boundary condition at the surface. In the blackbody approximation, the surface heat flux

$$
F=\sigma_{B} T_{s}^{4}
$$

where $\sigma_{B}$ is the Stefan-Boltzmann constant and $T_{s}$ is the surface temperature.

For low viscosity magma, convection is in a turbulent regime (Kraichnan, 1962; Shraiman and Siggia, 1990; Siggia, 1994). Neglecting the effect of rheological variations near the surface, the heat flux in the soft turbulence regime

$$
F=0.089 k\left(T-T_{s}\right)^{4 / 3}\left(\frac{\rho_{l} \alpha g}{\eta_{l} \kappa}\right)^{1 / 3}
$$

where $T$ is the potential temperature. The convective heat flux must match the radiative heat flux at the surface. In the blackbody approximation, at a potential temperature of $2000 \mathrm{~K}$, the surface temperature and heat flux are $\sim 1400 \mathrm{~K}$ and $3 \times 10^{5} \mathrm{~W} / \mathrm{m}^{2}$, respectively. 
The timescale for crystallization to the critical melt fraction

$$
t_{\text {crys }} \approx \frac{\left[L\left(1-\phi_{c r}\right)+c_{p} \Delta T\right] M}{F S}
$$

where the mass $M=\rho V$ and $S=\pi R^{2}$. For the variation of melt fraction between liquidus and solidus suggested by the experimental data of McKenzie and Bickle, (1988), the temperature change corresponding to $\Delta \phi=1-\phi_{c r}$ is $\Delta T \approx 0.4\left(T_{l}-T_{s}\right) \approx 0.4(2000-1400) \mathrm{K} \approx 240 \mathrm{~K}$. For local magma ocean size $R \sim 1000 \mathrm{~km}$, the crystallization time $t_{\text {crys }} \sim 300 \mathrm{yr}$.

Development of a stable, stagnant lid (Davaille and Jaupart, 1993) reduces the convective driving temperature. The rheological temperature scale which drives convection beneath the lid

$$
\Delta T_{d, m} \sim\left|\frac{\partial \ln \eta}{\partial T}\right|^{-1} \sim\left[\frac{E_{m}}{R T^{2}}\right]^{-1}
$$

where $E_{m}$ and $R$ are the activation energy and gas constant, respectively. The activation energy of olivine tholeiite melt at $1 \mathrm{GPa} E_{m} \sim 250 \mathrm{~kJ} / \mathrm{mol}$ (Kushiro, 1986). The convective heat flux in the stagnant lid regime (Solomatov and Moresi, 2000),

$$
F=0.53 k \Delta T_{d, m}^{4 / 3}\left(\frac{\rho_{l} \alpha g}{\eta_{l} \kappa}\right)^{1 / 3}
$$

At a temperature $T \sim 2000 \mathrm{~K}, \Delta T_{d, m} \sim 100 \mathrm{~K}$ and $F \sim 10^{5} \mathrm{~W} / \mathrm{m}^{2}$, a factor of 3 smaller than the surface recycling case. However, the stability of a viscous lid with thickness on the order of centimeters (the thickness $\sim k \Delta T / F$ with $\Delta T \sim 1000 \mathrm{~K}$ ) seems unlikely due to continuing impact disruption and convective stress induced recycling.

Impacts of the sizes considered here distribute vaporized and molten ejecta around the planet and inject water into the atmosphere (Sleep and Zahnle, 1998; Segure et al., 2002) which acts as a greenhouse gas. A steam atmosphere significantly reduces the ability of the atmosphere to radiate in the infrared (Matsui and Abe, 1986; Zahnle et al., 1988; Kasting et al., 1988). For large amounts 
of water, an abrupt atmospheric transition from low to near melting surface temperature occurs for an outgoing radiative flux of $\sim 300 \mathrm{~W} / \mathrm{m}^{2}$. The present-day net solar flux at Mars is $\sim 100 \mathrm{~W} / \mathrm{m}^{2}$. If a steam atmosphere limits surface heat flux to $200 \mathrm{~W} / \mathrm{m}^{2}$, the magma ocean crystallization time increases by a factor of $\sim 1000$ compared to the blackbody model. On the other hand, at even higher surface temperatures, the atmosphere can radiate at a much higher rate due to increased transparency in the visible and near infrared (Zahnle et al., 1988). The effect of a thick atmosphere and high surface temperature on local magma ocean evolution requires further study.

\section{Isostatic adjustment to a local magma ocean}

Because the melt region density is less than the density of solid silicates, the melt region is positively buoyant and the planet deforms in order to restore isostatic equilibrium. The isostatic adjustment timescale depends on the melt region size and the effective viscosity of the solid part of the planet. A crude, zero-order estimate of the radial relaxation timescale can be made based on Stokes flow of an inviscid sphere of radius $R$ through a distance $R$,

$$
t_{\text {iso }} \sim 3 \frac{\eta_{s}}{\left(\rho_{l}-\rho\right) g R}
$$

with solid planet viscosity $\eta_{s}$ (e.g., Karato and $\mathrm{Wu}, 1993$ ), liquid silicate density $\rho_{l}$, and solid silicate density $\rho$. For nominal parameters (Table 1 ) and $R \sim 1000 \mathrm{~km}, t_{\text {iso }} \sim 3 \times 10^{4} \mathrm{yrs}$.

For $t_{\text {crys }} \ll t_{\text {iso }}$, the melt region crystallizes to the critical crystal fraction before melt is redistributed by isostatic adjustment of the planet. For the blackbody model and $R \sim 1000 \mathrm{~km}$, convection with surface recycling or a stagnant lid yields an isostatic adjustment time $\sim 100-30$ times larger than the crystallization time. A critical parameter controlling whether a melt region evolves as a global magma ocean or local partial melt pond is the rheology of the solid part of the planet, $\eta_{s}$. Strongly temperature dependent effective mantle viscosity implies that Mars thermal 
state at the time of the impact plays a crucial role. Additionally, non-Newtonian rheology may dominate at higher stress levels, i.e. larger local magma ocean sizes. If a thick atmosphere significantly reduces the surface heat flux, the resulting long crystallization time facilitates development of a global magma ocean. For sufficiently large local magma oceans, the isostatic adjustment time could be greatly reduced. For a local magma ocean size $R \sim 1000 \mathrm{~km}$, the differential stress $\left(\rho-\rho_{l}\right) g R \sim 1 \mathrm{GPa}$ which is close to the power law creep breakdown stress (Tsenn and Carter, 1987) of $\sim 10^{-2} \mu$ with shear modulus $\mu$. Furthermore, this differential stress approaches the ultimate strength of rocks $\sim 1$ - 2 GPa (Davies 1982; Kinsland, 1978). In these cases, isostatic adjustment could be extremely fast. The viscous isostatic adjustment model probably only holds below an upper limit of $R / R_{p} \sim 0.5$.

\section{Isostatic adjustment to a partially molten local magma ocean}

Subject to the caveats of the previous section and within the uncertainties of various parameters, it is possible for a local magma ocean to crystallize in place prior to development of a global layer. After local magma ocean crystallization to the critical crystal fraction, several changes occur which affect the evolution. Crystallization reduces the driving density difference for radial relaxation. A more significant effect is the rheological transition from a liquid to a partially molten solid which greatly increases the viscosity. Recent experiments (Hirth and Kohlstedt, 1995a; 1995b; Kohlstedt and Zimmerman, 1996; Hirth and Kohlstedt, 2003; Scott and Kohlstedt, 2004a; 2004b) suggest that the viscosity $\eta_{m} \sim \eta_{s} \exp \left(-\alpha_{\eta} \phi\right)$ where $\alpha_{\eta} \sim 25$ (Scott and Kohlstedt, 2004b). The viscosity drops by 1-2 orders of magnitude for $\phi \sim 0.1-0.2$. For this study, the viscosity of partially molten material $\eta_{m} \sim 10^{17} \mathrm{~Pa}$ s. Additionally, at sufficiently high stresses, the material can fail. The low pressure yield strength of rocks (coherence strength) $\tau_{y} \sim 10-100 \mathrm{MPa}$ and increases with pressure (frictional law). 
For the much higher viscosity, $\eta_{m}$, the convective cooling time increases dramatically. Although melt migration in the partially molten local magma ocean can occur before any further convective cooling, partial melt region buoyancy drives isostatic adjustment on a timescale that is small compared to melt migration. Isostatic adjustment involves both a radial and lateral component, i.e., the partial melt region moves radially outward and spreads laterally until spherical symmetry is restored. While the timescale for radial relaxation is controlled by the rheology of the solid mantle, the lateral component of isostatic adjustment involves deformation of the melt region itself.

The percolation velocity of melt through the solid matrix

$$
v_{p e r c}=\frac{k_{\phi}\left(\rho-\rho_{l}\right) g}{\eta_{f}} \frac{(1-\phi)}{\phi}
$$

In the low Reynolds number limit, the Ergun equation for $k_{\phi}$ (Ergun, 1952) reduces to the BlakeCarman-Kozeny equation (e.g., Bird et al., 1960),

$$
k_{\phi}=\frac{\phi^{3} D_{p}^{2}}{150(1-\phi)^{2}} \text {, }
$$

where $D_{p}$ is the grain size. For $D_{p} \sim 3 \mathrm{~mm}$ and $\phi \sim 3 \%, k_{\phi} \sim 10^{-12} \mathrm{~m}^{2}$. Near the solidus, partial melt viscosity is higher due to lower temperatures. At low pressures, basaltic melt viscosity formed near the anhydrous solidus $\eta_{f} \sim 100 \mathrm{~Pa}$ s (Kushiro, 1980; 1986) depending on composition and, in particular, silica content which affects degree of polymerization. For this value of $\eta_{f}$ and a local magma ocean size $R \sim 1000 \mathrm{~km}$, the timescale for percolation to reduce the melt fraction to $3 \%$ $t_{\text {perc }} \sim 10^{8}$ yrs.

At the critical melt fraction, $\phi_{c r}$, the density difference which drives isostatic adjustment $\rho_{s}-$ $\rho_{c r}=\left(\rho_{s}-\rho_{l}\right) \phi_{c r} \sim 300 \mathrm{~kg} / \mathrm{m}^{3}$. The Stokes' flow estimation for the radial relaxation time (Eq. 
10) is increased by a factor of $\left(\rho_{s}-\rho_{l}\right) /\left(\rho_{s}-\rho_{c r}\right) \sim \phi_{c r}^{-1} \sim 3$. For nominal parameters (Table 1) and $R \sim 1000 \mathrm{~km}, t_{\text {iso }} \sim 10^{5}$ yrs. Thus, isostatic adjustment is fast compared to melt percolation.

Partially molten material extruded onto the surface spreads laterally to complete the process of isostatic adjustment. The lateral spreading time is estimated from an axisymmetric gravity current model. Depending on local magma ocean size and radial relaxation rate, the gravity current can be in a viscous regime or yield stress regime (Fig. 4).

For nominal parameters (Table 1), and sufficiently large volume flux, $Q \sim V / t_{\text {iso }}$, basal shear stresses can exceed the yield stress. In this case, the gravity current radius (Nye, 1951; Blake, 1990),

$$
S \sim\left(\frac{\rho_{c r} g Q^{2}}{\tau_{y}}\right)^{1 / 5} t^{2 / 5}
$$

where $\rho_{\text {cr }}$ is the density at the critical melt fraction, and $\tau_{y}$ is the yield stress. The flow thickness

$$
Z \sim\left(\tau_{y} Q^{1 / 2} / \rho_{c r} g\right)^{2 / 5} t^{1 / 5}
$$

The criterion that the flow area equal the planetary surface area $S^{2} \sim 2 R_{p}^{2}$ gives the spreading time.

For the driving force - yield stress balance to dominate throughout spreading, $\eta_{m} U / Z \gg \tau_{y}$ with characteristic spreading velocity $U \sim R_{p} / t_{\text {sprd }}$. The criterion for plastic spreading gives a critical volume flux

$$
Q_{\mathrm{cr}} \gg 4 \pi^{2 / 5} R_{p}^{2} \tau_{y}^{2} /\left(\rho_{c r} g \eta_{m}\right)
$$

For nominal parameters (Table 1), $Q_{\mathrm{cr}} \sim 6 \times 10^{6} \mathrm{~m}^{3} / \mathrm{s}$ corresponding to $R_{\mathrm{cr}} \sim 1700 \mathrm{~km}$. The spreading time at this transition $t_{\mathrm{sprd}} \sim 10^{3}$ yrs implying that radial relaxation limits isostatic adjustment.

Below the transition local magma ocean size, $R_{\mathrm{cr}}$, the volume flux drops below the critical one for basal yielding, $Q<Q_{\mathrm{cr}}$, and spreading proceeds in a viscous regime. Another implication 
is that the lateral spreading time becomes larger than the radial relaxation time implying that a constant volume flow condition is more appropriate. Surface cooling results in large rheological variations within the flow. For sufficiently large crustal viscosity, flow can be controlled by crustal deformation at the flow periphery (Griffiths, 2000). However, for the large scale flows considered here, the crust yields and dynamics are controlled by deformation of the bulk. Thus, we consider a rheologically uniform flow and bulk cooling as the flow limiting process. For an axisymmetric, viscous, constant volume, divergent gravity current, the radius (Huppert, 1982; Gratton et al., 1993)

$$
S \sim \pi^{-3 / 8}\left(\frac{\rho_{c r} g V^{3}}{\eta_{m}}\right)^{1 / 8} t^{1 / 8}
$$

and thickness

$$
Z \sim\left(\eta_{m} V /\left(\rho_{c r} g\right)\right)^{1 / 4} t^{-1 / 4}
$$

The spreading timescale in this regime increases from $t_{\mathrm{sprd}} \sim 10^{5} \mathrm{yr}$ for $R \sim R_{\mathrm{cr}}$ to $10^{7} \mathrm{yr}$ at $R \sim 1000 \mathrm{~km}$

The bulk viscosity of the flow increases with time due to cooling which slows and eventually stops the flow (Sakimoto and Zuber, 1995; Bercovici and Lin, 1996). Spreading should essentially stop after approximately one diffusion time. For cooling from above and below this time satisfies $Z / 2 \sim 2\left(\kappa t_{\text {cool }}\right)^{1 / 2}$. In the viscous regime, the cooling time $t_{\text {cool }} \sim 10^{6}$ yr. For $t_{\text {sprd }} \gg t_{\text {cool }}$, the

partial melt cools and spreading stops before a global layer forms. For $R \sim 1000 \mathrm{~km}, t_{\mathrm{sprd}} \sim 10^{7}$ yrs while the cooling time is an order of magnitude smaller, $t_{\text {cool }} \sim 10^{6}$ yrs.

\section{Hypothesis for the origin of the hemispherical dichotomy and Tharsis}

A hypothesis for dichotomy and Tharsis formation in the context of local magma ocean evolution has recently been suggested (Reese and Solomatov, 2006). In this scenario, an impact induced 
local magma ocean rapidly crystallizes and isostatic adjustment produces a global layer of partially molten silicates with a degree-1 asymmetry (Fig. 5). A second smaller impact occurs after isostatic adjustment to the first partially molten magma ocean is complete. This local magma ocean crystallizes and its size is such that the lateral spreading component of isostatic adjustment proceeds in a viscous regime. In this case, bulk cooling results in cessation of spreading and formation of a large axisymmetric dome of material (Fig. 5). Both the dichotomy and Tharsis are the result of similar processes of local magma ocean evolution the only difference being the size of the initial, impact induced melt regions.

In the context of this hypothesis, the earliest formed Martian crust is simply the solidified partial melt layer produced by the earlier and larger of the two impacts. A mean crustal thickness of 50 $\mathrm{km}$, corresponding to $4.4 \%$ of the planetary volume (Zuber, 2001), requires a local magma ocean size of $R \sim 1700 \mathrm{~km}$ (Eq. 5). This value of $R$ coincides with $R_{\mathrm{cr}}$ in which case lateral spreading occurs in yield stress controlled regime and takes $\sim 10^{4} \mathrm{yr}$. The layer thickness decreases from $Z \sim\left(4 \tau_{y} R_{p} /\left(\rho_{c r} g\right)\right)^{1 / 2} \sim 100 \mathrm{~km}$ on axis to near zero at the antipode (Fig. 5). Of course, while this layer continues to cool and solidify it also can relax viscously. Long-term preservation of the thickness variation depends on the mean thickness and viscosity structure (Zuber et al., 2000; Nimmo and Stevenson, 2001).

Formation of Tharsis can be due to the evolution of a smaller impact induced melt region. At the low end of the $R$ range, the retained, complete melt volume is $\sim 5 \times 10^{17} \mathrm{~m}^{3}$. This is of the order of the volume estimated for magmatic material comprising Tharsis (Phillips et al., 2001). The distribution of this material after isostatic adjustment can be estimated from the viscous lateral spreading model (Eq. 19). For a cooling time $\sim 10^{6} \mathrm{yrs}$, the radius $S \sim 3000 \mathrm{~km}$ corresponding to an area of $\sim 25 \%$ of the planetary surface area. The central thickness at the cessation of spreading 
is $Z \sim\left(\eta_{m} V /\left(\rho_{c r} g\right)\right)^{1 / 4} t_{c o o l}^{-1 / 4} \sim 20 \mathrm{~km}$. Crustal thickness variability within Tharsis (Zuber et al., 2000; Zuber, 2001) may be related to regionally enhanced melting.

\section{NUMERICAL SIMULATIONS OF THE INTERACTION BETWEEN LOCAL MAGMA OCEAN EVOLUTION AND MANTLE DYNAMICS}

While a fully coupled simulation of magma ocean processes and mantle convection is beyond the scope of this study, some important features of the problem can be addressed. As cooling and crystallization proceeds, the melt fraction and driving density difference for isostatic adjustment decrease, the viscosity increases, and the magma ocean processes discussed in the previous section slow down. At some point the dynamics merge with longer timescale, convective processes in the mantle.

\section{Initial temperatures}

The initial mantle temperature is not well constrained. While early core formation implies high temperatures (Stevenson, 2001), no thermal model of Mars formation produces high temperatures in the deep interior (Senshu et al, 2002). Here, an initial mantle temperature $T_{i, 0}=1700 \mathrm{~K}$ is assumed. The surface temperature $T_{s}=220 \mathrm{~K}$. The initial cold boundary layer thickness is controlled by the accretion timescale $\delta_{0} \sim 2\left(\kappa t_{a c c}\right)^{1 / 2}$. Due to viscosity gradient limitations of the numerical method, a thicker boundary layer must be considered $\delta_{0} \sim 300 \mathrm{~km}$. The mantle is near the solidus at the base of the cold boundary layer.

The initial temperature difference between the core and mantle, $\Delta T_{c m b, 0}=T_{c m b, 0}-T_{i, 0}$, with initial core mantle boundary temperature $T_{c m b, 0}$, depends on partitioning of gravitational energy released during core formation (Flasar and Birch, 1973). The existence of an early dynamo (Stevenson, 2001) provides constraints. In the absence of surface recycling, $\Delta T_{c m b, 0} \sim 150-200 \mathrm{~K}$ is sufficient to sustain a transient dynamo (Williams and Nimmo, 2004). For the purposes of this 
numerical model, $T_{c m b}$ is considered as a fixed adjustable parameter (Table 2).

\section{Viscosity}

An exponential temperature dependent viscosity law is used

$$
\eta=b \exp (-\gamma T)
$$

where $b$ and $\gamma$ are constant and chosen to fix the initial interior viscosity $\eta_{i, 0}=\eta\left(T_{i, 0}\right)$ and the initial viscosity contrast between the surface and mantle $\Delta \eta_{0}=\exp \left(\gamma\left(T_{i, 0}-T_{s}\right)\right)=10^{2}$. A rigid upper surface boundary condition results in a relatively immobile lithosphere.

\section{Internal heating}

Geochemical analyses suggest early separation of a radiogenic isotope enriched crust (McLennan, 2001). The internal heating rate

$$
H(t)=C_{d} H_{0} \exp (-\lambda t)
$$

with depletion factor $C_{d}$ (Table 2), initial specific heat production $H_{0}$ and decay constant $\lambda$ (Table 1).

\section{Melting}

Mantle solidus is parameterized according to experimental data for peridotite (Scarfe and Takahashi, 1986; Ito and Takahashi, 1987; McKenzie and Bickle, 1988; Herzberg and Zhang, 1994),

$$
T_{m}=1374+130 p-5.6 p^{2},
$$

where $T_{m}$ and $p$ are in Kelvin and GPa, respectively. After the slope reaches $d T_{m} / d p=10 \mathrm{~K} / \mathrm{GPa}$, $T_{m}$ increases linearly with pressure. Only dry melting at pressures below $\sim 8 \mathrm{GPa}$ is considered. The melt fraction

$$
f=\frac{c_{p}}{L}\left(T-T_{m}\right)
$$


Model parameters (Table 1 ) imply a melting rate of $\sim 0.2 \% / \mathrm{K}$ above solidus. All melt is assumed to be immediately extracted from the mantle resulting in crustal growth through intrusive and extrusive magmatism.

\section{Crustal growth and spreading}

Crustal thickness variations generate lateral pressure gradients which drive crustal deformation resulting in relaxation of topographic relief. Crustal spreading can be addressed using a viscous (Nimmo and Stevenson, 2001) or viscoelastic (Zuber et al., 2000) rheology. The spatially localized and high melting rates for the models considered here generate very large lateral pressure gradients, in excess of the cohesive strength of rocks. This motivates an alternative crustal spreading model based on a yield strength criterion.

When the product of the topographic relief and slope, $\zeta=z(\theta, \varphi)|\nabla z(\theta, \varphi)|$, reaches some critical value $\zeta_{c r}$, material is rapidly redistributed. Here, $\theta$ and $\varphi$ are the spherical coordinate polar and azimuthal angles, respectively. This is idea is implemented by requiring $z$ to satisfy a nonlinear diffusion equation with transport coefficient that increases rapidly as $\zeta \rightarrow \zeta_{c r}$. During crustal growth, the conditions of isostacy and $\zeta<\zeta_{c r}$ are maintained. The crustal structure predicted by this model would be subject to further viscous or viscoelastic relaxation (Zuber et al, 2000; Nimmo and Stevenson, 2001).

\section{Partially molten local magma oceans}

Local magma ocean conditions can be mimicked by including a partially molten, buoyant region in the simulation. This condition is approximated by choosing a suitably large magma ocean temperature $T_{\text {ocean }}$. In the numerical model, initial magma ocean buoyancy is due solely to thermal expansion. In contrast, the driving buoyancy for isostatic relaxation in the scaling analysis is due to the melt-solid density difference. Production of melt associated with isostatic adjustment of the 
partial melt region is governed by Eqs. (23) and (24).

With this approach, the extrusion volume $V$ can be calibrated with the scaling analysis result (Eq. 5) by adjusting $T_{\text {ocean }}$. For the cases considered here, $T_{\text {ocean }}(p)=T_{m}(p)$ and the driving density difference $\Delta \rho \sim \rho \alpha\left(T_{m}-T_{i, 0}\right) \sim 30 \mathrm{~kg} / \mathrm{m}^{3}$. This is about an order of magnitude smaller than $\Delta \rho$ due to the partial melt-solid density difference and, thus, the isostatic adjustment time increases by an order of magnitude.

Two local magma oceans are included in the numerical models according to the hypothesis of Section 3. The larger and earlier magma ocean has axis of symmetry about the south pole, size $R \sim 1700 \mathrm{~km}$ and time of formation $t=0.0$ Gyr (Figures 6-8). The axis of symmetry of the second, smaller, magma ocean passes through $0^{\circ} \mathrm{N}, 248^{\circ} \mathrm{E}$. The size $R \sim 1000 \mathrm{~km}$ and the time of formation $t=0.1$ Gyr (Figure 6-8).

To model the initial rapid redistribution of partial melt associated with the larger magma ocean, all melt produced during the first 0.1 Gyr is redistributed axisymmetrically about the planet according to $z(\theta, \varphi)=V /\left(2 \pi R_{p}^{2}\right) \theta / \pi$, with $\theta$ in radians. All subsequent melt is superposed on this initial distribution and subject to the crustal spreading model.

\section{Convection equations and numerical method}

In the large Prandtl number limit, which neglects inertial terms in the momentum balance, and the Boussinesq approximation, where density variation are neglected everywhere except in the buoyancy term, the equation of convection expressing conservation of mass, momentum and energy are

$$
\begin{gathered}
\frac{\partial u_{i}}{\partial x_{i}}=0 \\
\frac{\partial \tau_{i} j}{\partial x_{j}}=-\frac{\partial p}{\partial x_{i}}+\alpha \rho g_{i}
\end{gathered}
$$




$$
\rho c_{p}\left(\frac{\partial T}{\partial t}+u_{i} \frac{\partial T}{\partial x_{i}}\right)=k \frac{\partial^{2} T}{\partial x_{j} \partial x_{j}}+\rho H-\rho L \frac{\partial f}{\partial t},
$$

with spatial coordinates $x_{i}$, time $t$, velocity $u_{i}$, dynamic pressure $p$, coefficient of thermal expansion $\alpha$, gravitational acceleration $g_{i}$, temperature $T$, specific heat at constant pressure $c_{p}$, thermal conductivity $k$, specific heat production rate $H$, latent heat of fusion $L$, and melt fraction $f$. The deviatoric stress tensor

$$
\tau_{i j}=\eta\left(\frac{\partial u_{i}}{\partial x_{j}}+\frac{\partial u_{j}}{\partial x_{i}}\right)
$$

The fully three-dimensional spherical shell geometry code TERRA is used to study the effect of local magma oceans on Martian mantle convection and magmatic evolution (Baumgardner, 1985; Bunge and Baumgardner, 1995, Reese et al., 2004).

\section{NUMERICAL SIMULATION RESULTS}

In this section, numerical simulation results are summarized. Particular attention is focused on early magmatic evolution (Table 2), crustal structure (Figs. 6-8), and conditions for which melting continues at lower levels to the present-day (Fig. 9). Three models are considered in which the the core mantle boundary temperature, depletion factor and initial interior viscosity were varied (Table 3).

\section{Noachian evolution}

The thermal and magmatic evolution for the first $1 \mathrm{Gyr}$ of Martian evolution for these cases are summarized in Figs. (6-8). To isolate the effect of the local magma oceans, a model with no internal or bottom heating was considered (Model A, c.f. Reese et al., (2004)). For this case, the initial magma ocean results in a crustal thickness that decreases from $\sim 30 \mathrm{~km}$ to $0 \mathrm{~km}$ from the south to north pole. Small-scale lithospheric instabilities are developed in the southern hemisphere by $\sim 0.3$ Gyr and no signature of the initial upwellings associated with the local magma oceans 
remains after this time. The melting rate decreases by four orders of magnitude in $\sim 1$ Gyr with a pulse at $\sim 0.7$ corresponding to onset of small scale convection in the northern hemisphere. The thickest crust is in Tharsis province. In the absence of any source of internal heat, mantle cooling results in unrealistically low interior temperatures (mid-shell temperature of $\sim 1400 \mathrm{~K}$ at $1 \mathrm{Gyr}$ ).

Model B has modest internal and bottom heating (Table 2) and the same initial interior viscosity as Model A. The initial crustal structure associated with the first magma ocean is primarily determined by $T_{\text {ocean }}$ and $\eta_{i, 0}$ and thus approximately the same as that of Model A. Vigorous plumes and lithospheric instabilities result in efficient thermal homogenization which removes any signature of the initial upwellings. While the maximum crustal thickness of $\sim 70 \mathrm{~km}$ again occurs in Tharsis province (Fig. 7), there is also significant melting in the northern hemisphere. The melting rate decreases by two orders of magnitude over the Noachian epoch.

Model $\mathrm{C}$ has stronger bottom heating and an initially more viscous mantle (Table 2). The initial crustal thickness is much smaller due to the fact that the extrusion rate $\sim t_{\text {iso }}^{-1} \sim \eta_{i, 0}$. Subsequent magmatism and crustal growth is confined to the southern hemisphere and Tharsis region. In contrast to Models A and B, the local magma oceans produce mantle plumes that remain stable throughout the Noachian. In fact, these plumes remain stable throughout planetary evolution. The thickest crust occurs at the south pole. The melting rate decreases from the initial value but is actually increasing at the end of the Noachian (Fig. 8).

\section{Hesperian-Amazonian evolution}

The magmatic evolution of the models after $1 \mathrm{Gyr}$ depends strongly on the value of $T_{c m b}$ (Table 2, Fig. 9) and the interior viscosity. For model A, the magmatic rate is zero after $\sim 1$ Gyr. In the case of model $\mathrm{B}$, the magmatic rate decays gradually to zero by $\sim 3$ Gyr followed by episodes of melting with rates peaking at $\sim 0.003 \mathrm{~km}^{3} / \mathrm{yr}$ continuing until present day. Model C exhibits 
a pulse in the melt production rate just after $1 \mathrm{Gyr}$ associated with plume head melting and a relatively constant rate of $\sim 0.1 \mathrm{~km}^{3} / \mathrm{yr}$ from $\sim 2$ Gyr to present day.

The existence of young volcanism on Mars (Hartmann et al., 1999) must be addressed by any mantle convection model (see e.g., Kiefer, 2003). Constraints on the present day melt production rate are provided by cratering studies. An estimate for the resurfacing rate during the middle to late Amazonian is $\sim 0.01 \mathrm{~km}^{2} / \mathrm{yr}$ (Hartmann and Neukum, 2001). Assuming that resurfacing of small craters on young surface flows require a depth of $\sim 10 \mathrm{~m}$ and an extrusive to intrusive efficiency of $\sim 10 \%$ implies that a lower bound on the present-day melting rate is $10^{-3} \mathrm{~km}^{3} / \mathrm{yr}$. Model B just satisfies this requirement while Model C produces significantly more melt (Fig. 9).

The present day model topography can be compared to Mars Global Surveyor (MGS) topography (Fig. 10). While no single model produces a significant quantitative correlation with observation, individual features of the models are intriguing. The long-wavelength patterns of topography for Models A and B agree qualitatively with observation. Model B western hemisphere topography reproduces the approximate size, location and scale of Tharsis province. In both Models A and B, superimposed on the north to south topographic slope are small scale features generated by melting associated with lithospheric instabilities. Model $\mathrm{C}$ produces upwelling plumes from the core mantle boundary that remain stable throughout planetary evolution. There are four strong plumes, one beneath the southern hemisphere and three in the Tharsis region. The topography is the surface expression of local magma ocean evolution and continued melting in the plume heads. One interesting possibility is that the Elysium volcanic province corresponds to a stable plume as in Model C, or melting induced by lithospheric instability as in Model A or B.

\section{DISCUSSION AND CONCLUSIONS}

Formation of local magma oceans are one process that can shape the initial thermal and com- 
positional state of the planet. The effects of local magma ocean evolution on crust formation, core formation, and development of geochemical reservoirs in the mantle can provide a fundamental framework for understanding early Mars evolution. In this study, the implications of local magma oceans for rapid development of large scale crustal structure on early Mars were addressed. In particular, a hypothesis for formation of the hemispherical crustal dichotomy and Tharsis based on local magma ocean evolution (Reese and Solomatov, 2006) was further explored using threedimensional spherical shell simulations.

The models considered produce crustal volumes that are of the same order of magnitude as the observed value. The average crustal thicknesses for Models A, B, and C are $\sim 20$, 40, and $10 \mathrm{~km}$, respectively. The observed value is $\sim 50 \mathrm{~km}$ (Zuber, 2001). Crustal structure varies between models. In general, all models exhibit a south to north thinning trend and thickening in the Tharsis region. Models A and B predict small scale variations attributed to melting associated with lithospheric instabilities. Model C produces plume head melting beneath the southern hemisphere and for three plumes in the Tharsis region. The present day melting rate is another observational constraint. Melting ceases in Model A at $\sim 1$ Gyr, episodes of melting with peak rates $\sim 3 \times 10^{-3}$ $\mathrm{km}^{3} / \mathrm{yr}$ continue to present-day in Model B, and Model C has an approximately constant melting rate of $0.1 \mathrm{~km}^{3} / \mathrm{yr}$ after $\sim 2$ Gyr. To resurface $10 \mathrm{~m}$ topography, the present day value $\sim 10^{-3}$ $\mathrm{km}^{3} / \mathrm{yr}$.

This preliminary study motivates several topics which can be addressed in future work:

1. Young volcanism on Mars seems to require some degree of internal and/or bottom heating (e.g. Models B,C and Kiefer, (2003)). In this study, $T_{c m b}$ was fixed but in reality depends on the coupled thermal evolution of the mantle and core. The existence of a transient dynamo (Stevenson, 2001) is a strong constraint on the early core heat flux (Nimmo and Stevenson, 2000; Williams and 
Nimmo, 2004). Thermal evolution of the core can be included in the models to address dynamo constraints.

2. The stability of a plume or plumes beneath Tharsis throughout Martian evolution remains an outstanding question. While Model C produces three stable plumes in the western hemisphere, it also predicts a large plume beneath the southern hemisphere. This disagrees with the observation of middle-late Noachian volcanism focused at Tharsis and geologically recent volcanism limited to Tharsis and Elysium. The long duration of the Tharsis plume/plumes relative to the initial upwelling beneath the southern hemisphere must be addressed by future work.

3. No crust-mantle feedback was considered in the models. Enrichment of the crust in heat producing elements can lead to higher Moho temperatures in the southern hemisphere where the crust is thick. This asymmetry in the mantle surface temperature can have important implications for mantle dynamics (Lenardic and Moresi, 2003, Wenzel et al., 2004).

4. Preservation of early formed geochemical reservoirs for 4.5 Gyr (e.g., Kleine, 2004) is difficult to reconcile with vigorous mantle mixing. The characteristic interior velocities for Models $\mathrm{B}$ and $\mathrm{C}$ correspond to $\sim 10$ and 3 mantle overturns, respectively. The mixing efficiency also depends on the planform of convection which in Model $\mathrm{C}$ remains relatively constant throughout evolution. Preservation of mantle compositional heterogeneity can be addressed in future work.

5. In this study, size and location of large impacts were specified. A preferable approach would be to generate impactor sizes from an appropriate distribution and specify impact locations randomly. One possible result is a global, laterally heterogeneous magma ocean produced by overlapping local magma oceans. Another possibility is that only local magma oceans are generated due to the small number of sufficiently large impacts during late stage accretion.

\section{REFERENCES}


Agnor, C.B., Canup, R.M., and Levison, H.F., 1999, On the character and consequences of large impacts in the late stage of terrestrial planet formation: Icarus, v. 142, p. 219-237.

Anderson, R.C., Dohm, J.M., Golombek, M.P., Haldemann, A.F.C., Franklin, B.J., Tanaka, K.L., Lias, J., and Peer, B., 2001, Primary centers and secondary concentrations of tectonic activity through time in the western hemisphere of Mars: J. Geophys. Res., v. 106, p. 20563-20586.

Andrade, E.N.C., 1952, Viscosity of liquids: Proc. Roy. Soc. London, v. A215, p. 36-43.

Banerdt, W.B., and Golombek, M.P., 2000, Tectonics of the Tharsis region of Mars: Insights from MGS topography and gravity: Lunar Planet. Sci. Conf., 31, \#2038.

Baumgardner, J.R., 1985, Three dimensional treatment of convective flow in the Earth's mantle: J. Stat. Phys., v. 39, p. 501-511.

Bercovici, D., and Lin, J., 1996, A gravity current model of cooling mantle plume heads with temperature dependent buoyancy and viscosity: J. Geophys. Res., v. 101, p. 3291-3309.

Blake, S., 1990, Viscoplastic models of lava domes, 뜨, Fink, J.H., ed., Lava Flows and Domes: Emplacement Mechanisms and Hazard Implications: Springer-Verlag, New York, pp. 88-128.

Bottinga, Y., and Weill, D.F., 1972, The viscosity of magmatic silicate liquids: A model for calculation: Amer. J. Sci., v. 272, p. 438-475.

Bottinga, Y., Richet, P., and Sipp A., 1995, Viscosity regimes of homogeneous silicate melts: Amer. Mineral., v. 80, p. 305-318.

Breuer. D., Yuen, D.A., Spohn, T., and Zhang, S., 1998, Three dimensional models of Martian mantle convection with phase transitions: Geophys. Res. Lett. v. 25, p. 229-232. 
Bunge, H.-P., and Baumgardner, J.R., 1995, Mantle convection modeling on parallel virtual machines: Comput. Phys., v. 9, p. 207-215.

Chambers, J.E., and Wetherill, G.W., 1998, Making the terrestrial planets: N-body integrations of planetary embryos in three dimensions: Icarus, v. 136, p. 304-327.

Chambers, J.E., 2004, Planetary accretion in the inner solar system: Earth Planet. Sci. Lett., v. 223, p. 241-252.

Elkins-Tanton, L.T., Zaranek, S.E., Parmentier, E.M., and Hess, P.C., 2005a, Early magnetic field and crust on Mars from magma ocean cumulate overturn: Earth Planet. Sci. Lett., v. 236, p. 1-12.

Elkins-Tanton, L.T., Hess, P.C., and Parmentier, E.M., 2005b, Possible formation of ancient crust on Mars through magma ocean processes: J. Geophys. Res., v. 110, E12S01, doi:10.1029/2005JE002480.

Flasar, F.M., and Birch, F., 1973, Energetics of core formation: a correction: J. Geophys. Res., v. 78, p. 6101-6103.

Frey, H., and Schultz, R.A., 1988, Large impact basins and the mega-impact origin for the crustal dichotomy on Mars: Geophys. Res. Lett., v. 15, p. 229-232.

Frey, H., Sakimoto, S.E., and Roark, J., 1998, The MOLA topographic signature at the crustal dichotomy boundary zone on Mars: Geophys. Res. Lett., v. 25, p. 4409-4412.

Frey H.V., Roark, J.H., Shockey, K.M., Frey, E.L., and Sakimoto, S.E.H., 2002, Ancient lowlands on Mars: Geophys. Res. Lett., v. 29, 10.1029/2001GL013832.

Gans, R.F., 1972, Viscosity of the Earth's core: J. Geophys. Res., v. 77, p. 360-366.

Gratton, J., Minotti, F., and Mahajan, S.M., 1999, Theory of creeping gravity currents of a non- 
Newtonian liquid: Phys. Rev. E, v. 60, p. 6960-6967.

Griffiths, R.W., 2000, The dynamics of lava flows: Annu. Rev. Fluid Mech., v. 32, p. 477-518.

Harder, H., 2000, Mantle convection and the dynamic geoid of Mars: Geophys. Res. Lett. v. 27, p. 301-304.

Harder, H., and Christensen, U.R., 1996, A one-plume model of Martian mantle convection: Nature, v. 380, p. 507-509.

Harper, C.L., Nyquist, L.E., Bansal, B., Wiesmann, H., and Shih, C.Y., 1995, Rapid accretion of early differentiation of Mars indicated by ${ }^{142} \mathrm{Nd} /{ }^{144} \mathrm{Nd}$ in SNC Meteorites: Science, v. 267, p. 213-217.

Hartmann, W.K., Malin, M., McEwen, A., Carr, M., Soderblom, L., Thomas, P., Danielson, E., James, P., and Ververka, J., 1999, Evidence for recent volcanism on Mars from crater counts: Nature, v. 397, p. 586-589.

Hartmann, W.K., and Neukum, G., 2001, Cratering chronology and the evolution of Mars: Space Sci. Rev., v. 96, p. 165-194.

Herzberg, C., and Zhang, J.Z., 1994, Melting experiments on anhydrous peridotite KLB-1 from 5.0 to 22.5 Gpa: J. Geophys. Res., v. 99, p. 17,729-17,742.

Hess, P.C., and Parmentier, E.M., 2001, Implications of magma ocean cumulate overturn for Mars: Lunar Planet. Sci. Conf., 32,\#1319.

Hirth, G., and Kohlstedt, D.L., 1995a, Experimental contraints on the dynamics of the partially molten upper mantle: Deformation in the diffusion creep regime: J. Geophys. Res., v. 100, p. 1981-2001. 
Hirth, G., and Kohlstedt D.L., 1995b, Experimental contraints on the dynamics of the partially molten upper mantle: Deformation in the dislocation creep regime: J. Geophys. Res., v. 100, p. $15,441-15,449$.

Hirth, G., and Kohlstedt, D.L., 2003, Rheology of the mantle wedge, in, Eiler, J., ed., Inside the Subduction Factory: Am. Geophys. Union, Washington D.C., p. 83-106.

Huppert, H.E., 1982, The propagation of two-dimensional and axisymmetric viscous gravity currents over a rigid horizontal surface: J. Fluid Mech., v. 121, p. 43-58.

Huppert, H.E., and Sparks, R.S.J., 1985, Komatiites I: Eruption and flow: J. Petrol., v. 26, p. 694-725.

Ito, E., and Takahashi, E., 1987, Melting of peridotite at uppermost lower mantle conditions: Nature, v. 328, p. 514-517.

Johnson, C.L., and Phillips, R.J., 2005, Evolution of the Tharsis region of Mars: Insights from magnetic field observations: Earth Planet. Sci. Lett., v. 230, p. 241-254.

Karato, S.-I., and Wu, P., 1993, Rheology of the upper mantle: A synthesis: Science, v. 260, p. $771-778$.

Kasting, J.F., 1988, Runaway and moist greenhouse atmospheres and the evolution of Earth and Venus: Icarus, v. 74, p. 472-494.

Kohlstedt, D.L., and Zimmerman, M.E., 1996, Rheology of partially molten mantle rocks: Annu. Rev. Earth Planet. Sci., v. 24, p. 41-62.

Kiefer, W.S., 2003, Melting in the martian mantle: Shergottite formation and implications for present-day mantle convection on Mars: Meteor. Planet. Sci., v. 39, p. 1815-1832. 
Kieffer, S.W., 1977, Impact conditions required for formation of melt by jetting in silicates, in, Roddy, D.J., Pepin, R.O., and Merril, R.B., eds., Impact and Explosion Cratering: Pergamon Press, New York, p. 751-769.

King, S.D., and Redmond, H.L., 2005. The crustal dichotomy and edge driven convection: A mechanism for Tharsis rise volcanism?: Lunar Planet. Sci. Conf, 36, \#1960.

Kleine, T., Mezger, K., Münker, C., Palme, H., and Bischoff, A., 2004, ${ }^{182}{ }^{H f-}{ }^{182}$ W isotope systematics of chondrites, eucrites, and martian meteorites: Chronology of core formation and early mantle differentiation in Vesta and Mars: Geochim. Cosmochim. Acta, v. 68, p. 2935-2946.

Kraichnan, R.H., 1962, Turbulent thermal convection at arbitrary Prandtl number, Phys. Fluids, v. 5, p. 1374-1389.

Lee, D.C., and Halliday, A.N., 1997, Core formation on Mars and differentiated asteroids, Nature, v. 388 , p. $854-857$.

Lemoine, F.G., Smith, D.E., Rowlands, D.D., Zuber, M.T., Neumann, G.A., Chinn, D.S., and Pavlis, D.E., 2001, An improved solution of the gravity field of Mars (GMM-2B) from Mars Global Surveyor, J. Geophys. Res., v. 106, p. 23359-23376.

Lenardic, A., and Moresi, L., 2003, Thermal convection below a conducting lid of variable extent: Heat flow scalings and two dimensional, infinite Prandtl number numerical simulations: Phys. Fluids, v. 15, p. 455-466.

Matsui, T., and Abe, Y., 1986, Evolution of an impact induced atmosphere and magma ocean on the accreting Earth: Nature, v. 319, p. 303-305.

McEwen, A.S., Malin, M.C., Carr, M.H., and Hartmann, W.K., 1999, Voluminous volcanism on 
early Mars revealed in Valles Marineris: Nature, v. 397, p. 584-586.

McKenzie, D., and Bickle, M.J., 1988, The volume and composition of melt generated by extension of the lithosphere: J. Petrol., v. 29, p. 625-679.

McLennan, S.M., 2001, Crustal heat production and the thermal evolution of Mars: Geophys. Res. Lett, v. 28, p. 4019-4022.

Melosh, H.J., 1989, Impact Cratering: A Geological Process: Oxford University Press, New York, USA.

Neukum, G. and 10 colleagues, 2004, Recent and episodic volcanic and glacial activity on Mars revealed by the High Resolution Stereo Camera: Nature, 432, p. 971-979.

Neumann G.A., Zuber, M.T., Wieczorek, M.T., McGovern, M.T., Lemoine, F.G., and Smith, F.G., 2004, Crustal structure of Mars from gravity and topography: J. Geophys. Res., v. 109, 10.1029/2004JE002262.

Nimmo, F., and Stevenson, D., 2000, The influence of early plate tectonics on the thermal evolution and magnetic field of Mars: J. Geophys. Res., v. 105, p. 11,969-11,979.

Nimmo, F., and Stevenson, D.J., 2001, Estimates of Martian crustal thickness from viscous relaxation of topography: J. Geophys. Res., v. 106, p. 5085-5098.

Nimmo, F., and Tanaka, K., 2005, Early crustal evolution of Mars: Annu. Rev. Earth Planet. Sci., v. 33 , p. $133-161$.

Nye, J.F., 1951, Mechanics of glacier flow: J. Glaciol., v. 2, p. 82-93.

Persikov, E.S., Zharkov, V.A., Bukhtiyarov, P.G., and Polskoy, S.F., 1990, The effect of volotiles 
on the properties of magmatic melts: Eur. J. Mineral., v. 2, p. 621-642.

Pierazzo, E., and Melosh, H.J., 2000, Melt production in oblique impacts: Icarus, v. 145, p. 252261.

Phillips, R.J., and 10 colleagues, 2001, Ancient geodynamics and global scale hydrology on Mars, Science, v. 291, p. 2587-2591.

Reese, C.C., and Solomatov, V.S., 2006, Fluid dynamics of local martian magma oceans: Icarus, v. 184, p. 102-120, 10.1016/j.icarus.2006.04.008.

Reese, C.C., Solomatov, V.S., Baumgardner, J.R., Stegman, D.R., and Vezolainen, A.V., 2004, Magmatic evolution of impact-induced Martian mantle plumes and the orgin of Tharsis: J. Geophys. Res., v. 109, 10.1029/2003JE002222.

Sakimoto, S.E.H., and Zuber, M.T., 1995, The spreading of variable viscosity axisymmetric radial gravity currents: Applications to the emplacement of Venus pancake domes: J. Fluid. Mech., v. 301, p. $65-77$.

Scarfe, C.M., and Takahashi, E., 1986, Melting of garnet peridotite to $13 \mathrm{GPa}$ and the early history of the upper mantle: Nature, v. 322, p. 354-356.

Schmidt, R.M., and Housen, K.R., 1987, Some recent advances in the scaling of impact and explosion cratering: Int. J. Impact Eng., v. 5, p. 543-560.

Scott, T., and Kohlstedt, D.L., 2004a, The effect of large melt fraction on the deformation behavior of peridotite: Implications for the rheology of Io's mantle: Lunar Planet. Sci. Conf., 35, \#1304.

Scott, T.J., and Kohlstedt, D.L., 2004b, The effect of large melt fraction on the deformation behavior of peridotite: Implications for the viscosity of Io's mantle and the rheologically critical melt 
fraction: Eos Trans. AGU, 85, \#4582.

Segura, T.L., Toon, O.B., Colaprete, A., and Zahnle, K., 2002, Environmental effects of large impacts on Mars: Science, v. 298, p. 1977-1980.

Senshu, H., Kuramoto, K., and Matsui, T., 2002. Thermal evolution of a growing Mars: J. Geophys. Res., v. 107, 10.1029/2001JE001819.

Shaw, H.R., 1972, Viscosities of magmatic silicate liquids: An empirical method of prediction, Am. J. Sci., v. 272, p. 870-893.

Shraiman, B.I., and Siggia, E.D., 1990, Heat transport in high Rayleigh number convection: Phys. Rev. A, v. 42, p. 3650-3653.

Siggia, E.D., 1994, High Rayleigh number convection: Annu. Rev. Fluid Mech., v. 26, p. 137-168.

Sleep, N.H., 1994, Martian plate tectonics: J. Geophys. Res., v. 99, p. 5639-5655.

Sleep, N.H., and Zahnle, K., 1998, Refugia from asteroid impacts on early Mars and early Earth: J. Geophys. Res., v. 103, p. 28,529-28,544.

Smith, D.E., and 18 colleagues, 1999, The global topography of Mars and implications for surface evolution: Science, v. 284, p. 1495-1503.

Smith, D. E., and 23 colleagues, 2001, Mars Orbiter Laser Altimeter: Experiment summary after the first year of global mapping of Mars: J. Geophys. Res., v. 106, p. 23,689-23,722.

Solomatov, V.S., 2000, Fluid dynamics of magma oceans, in, Canup, R., and Righter, K., eds., Origin of the Earth and Moon: Univ. Arizona Press, Tucson, p. 323-338.

Solomatov, V.S., and Stevenson, D.J., 1993a, Nonfractional crystallization of a terrestrial magma 
ocean: J. Geophys. Res., v. 98, p. 5391-5406.

Solomatov, V.S., and Stevenson, D.J., 1993b, Suspension in convective layers and style of differentiation of a terrestrial magma ocean: J. Geophys. Res., v. 98, p. 5375-5390.

Solomon, S.C., and Head, J.W., 1982, Evolution of the Tharsis province of Mars: The importance of heterogeneous lithospheric thickness and volcanic construction: J. Geophys. Res., v. 82, p. 9755-9774.

Solomon, S.C., and 16 colleagues, 2005, New perspectives on ancient Mars: Science, v. 307, p. $1214-1220$.

Spohn, T., Sohl, F., and Breuer, D., 1998, Mars: Astr. and Astrophys. Rev., v. 8, p. 181-235.

Stevenson, D.J., 2001, Mars core and magnetism: Nature, v. 412, p. 214-219.

Tonks, W.B., and Melosh, H.J., 1992, Core formation by giant impacts: Icarus, v. 100, p. 326-346.

Tonks, W.B., and Melosh, H.J., 1993, Magma ocean formation due to giant impacts: J. Geophys. Res., v. 98, p. 5319-5333.

Weinstein, S.A., 1995, The effects of a deep mantle endothermic phase change on the structure of thermal convection in silicate planets: J. Geophys. Res., v. 100, p. 11,719-11,728.

Wenzel M.J., Manga, M., and Jellinek, A.M., 2004, Tharsis as a consequence of Mars' dichotomy and layered mantle: Geophys. Res. Lett., v. 31, 10.1029/2003GL019306.

Wilhelms, D.E., and Squyres, S.W., 1984, The martian hemispheric dichotomy may be due to a giant impact: Nature, v. 309, p. 138-140.

Williams, J.-P., and Nimmo, F., 2004, Thermal evolution of the Martian core: Implications for an 
early dynamo: Geology, v. 32, p. 97-100.

Zahnle, K.J., Kasting, J.F., and Pollack, J.B., 1988, Evolution of a steam atmosphere during Earth's accretion, Icarus, v. 74, p. 62-97.

Zhong, S., and Zuber, M.T., 2001, Degree-1 mantle convection and the crustal dichotomy on Mars:

Earth Planet. Sci. Lett., v. 189, p. 75-84.

Zuber, M.T., 2001, The crust and mantle of Mars: Nature, v. 412, p. 220-227.

Zuber, M.T., and 14 colleagues, 2000, Internal structure and early thermal evolution of Mars from Mars Global Surveyor topography and gravity: Science, v. 287, p. 1788-1793. 
Table 1: Values of physical parameters

\begin{tabular}{|c|c|c|}
\hline Parameter & Symbol & Value \\
\hline Thermal capacity & $c_{p}$ & $1200 \mathrm{~J} / \mathrm{kg} \mathrm{K}$ \\
\hline Shock velocity parameter & C & $4.4 \mathrm{~km} / \mathrm{s}$ \\
\hline Cratering scaling parameter & $C_{D}$ & 1.6 \\
\hline Melt activation energy & $E_{m}$ & $250 \mathrm{~kJ} \mathrm{~mole}^{-1}$ \\
\hline Gravitational acceleration & $g$ & $3.7 \mathrm{~m} \mathrm{~s}^{-2}$ \\
\hline Specific heat production rate & $H_{0}$ & $2.1 \times 10^{-11} \mathrm{~W} / \mathrm{kg}$ \\
\hline Thermal conductivity & $k$ & $4 \mathrm{~W} \mathrm{~m}^{-1} \mathrm{~K}^{-1}$ \\
\hline Silicate latent heat of fusion & $L$ & $500 \mathrm{~kJ} \mathrm{~kg}^{-1}$ \\
\hline Mars mass & $M$ & $6.4 \times 10^{23} \mathrm{~kg}$ \\
\hline Mars radius & $R_{p}$ & $3398 \mathrm{~km}$ \\
\hline Gas constant & $R^{*}$ & $8.314 \mathrm{~J}$ mole $-1 \mathrm{~K}^{-1}$ \\
\hline Shock velocity parameter & $S$ & 1.5 \\
\hline Surface temperature & $T_{s}$ & $220 \mathrm{~K}$ \\
\hline Initial mantle temperature & $T_{i, 0}$ & $1700 \mathrm{~K}$ \\
\hline Impact velocity & $v_{i}$ & $7 \mathrm{~km} / \mathrm{s}$ \\
\hline Thermal expansion & $\alpha$ & $2 \times 10^{-5} \mathrm{~K}^{-1}$ \\
\hline Cratering scaling parameter & $\beta$ & 0.22 \\
\hline Thermal diffusivity & $\kappa$ & $10^{-6} \mathrm{~m}^{2} \mathrm{~s}^{-1}$ \\
\hline Decay constant & $\lambda$ & $3.3 \times 10^{-10} \mathrm{yr}$ \\
\hline Viscosity (solid) & $\eta_{s}$ & $10^{21} \mathrm{~Pa} \mathrm{~s}$ \\
\hline Viscosity (partial melt) & $\eta_{m}$ & $10^{17} \mathrm{~Pa} \mathrm{~s}$ \\
\hline Viscosity (liquid) & $\eta_{l}$ & $0.1 \mathrm{~Pa} \mathrm{~s}$ \\
\hline Viscosity (melt near solidus) & $\eta_{f}$ & $100 \mathrm{~Pa} \mathrm{~s}$ \\
\hline Solid silicate density & $\rho$ & $3500 \mathrm{~kg} \mathrm{~m}^{-3}$ \\
\hline Silicate density $\left(@ \phi_{c r}\right)$ & $\rho_{c r}$ & $3200 \mathrm{~kg} \mathrm{~m}^{-3}$ \\
\hline Liquid silicate density & $\rho_{l}$ & $2800 \mathrm{~kg} \mathrm{~m}^{-3}$ \\
\hline Stefan-Boltzmann constant & $\sigma_{B}$ & $5.67 \times 10^{-8} \mathrm{~W} \mathrm{~m}^{-2} \mathrm{~K}^{-4}$ \\
\hline Yield stress & $\tau_{y}$ & $10^{7} \mathrm{~Pa}$ \\
\hline Critical melt fraction & $\phi_{c r}$ & 0.4 \\
\hline Crustal spreading parameter & $\zeta_{c r}$ & 0.3 \\
\hline
\end{tabular}


Table 2: Martian epochs and ages

\begin{tabular}{lc}
\hline Epoch & Age $(\mathrm{Ga})$ \\
\hline Noachian & $4.5-3.5$ \\
Hepserian & $3.5-1.8$ \\
Amazonian & $1.8-0.0$ \\
\hline
\end{tabular}


Table 3: Adjustable model parameters

\begin{tabular}{lccc}
\hline Parameter & Model A & Model B & Model C \\
\hline$T_{c m b}(\mathrm{~K})$ & $\dagger$ & 1800 & 2000 \\
$C_{d}$ & 0 & 0.3 & 0.3 \\
$\eta_{i, 0}($ Pa s $)$ & $10^{21}$ & $10^{21}$ & $10^{22}$ \\
\hline
\end{tabular}

$\dagger$ insulating bottom boundary condition 
Figure 1: Hemispherical model of impact melt distribution. The radius of the region with melt fraction $\phi>\phi_{c r}$ is $R$, the impactor radius is $a$ and the relationship between the two is $R=1.7 a$ (see text).

Figure 2: (top) Comparison of impactor kinetic energies scaled by the Martian gravitational binding energy $E_{G}$ for different size events. Formation of a Hellas/Utopia size basin is based on a $200 \mathrm{~km}$ radius impactor with impact velocity $v_{i}$ (Table 1 ). The energy of a Moon forming impact on the proto-Earth is based on an impactor to target mass ratio $\sim 0.1$ and impact velocity equal to terrestrial escape velocity. (bottom) The effect of increasing impactor size on melt retained below the excavation zone (after Tonks and Melosh, (1992)).

Figure 3: Melt region crystallization. As the magma pond cools via convection, the temperature drops below the liquidus at the base of the melt region and crystallization proceeds from the bottom up. When the temperature decreases to the rheological transition temperature, a partially solid region develops and with further cooling, a rheological front propagates through the melt region.

Figure 4: Isostatic adjustment subsequent to initial crystallization. The initial distribution of the buoyant, partial melt region of size $R$ is shown with a line. Partially molten material is shaded grey. The timescale for radial relaxation is estimated from a simple Stokes' flow model. As buoyant material rises up, it flows out over the surface. The lateral spreading is estimated from an axisymmetric gravity current model. The height and radius of the lateral flow are $Z$ and $S$, respectively. In the model, it is assumed that all material is extruded and flows over a rigid, un- 
deformable surface. In reality, some material may flow beneath the lithosphere. Additionally, a deformable substratum would limit flow (coefficients in lateral spreading equations would change).

Figure 5: (top) The hypothesis for hemispherical crustal dichotomy and Tharsis formation. The dichotomy is associated with an early Noachian local magma ocean which quickly $\left(\sim 10^{4}-10^{5}\right) \mathrm{yr}$ evolves to a partially molten layer with a degree-1 asymmetry. During the middle-late Noachian, a smaller local magma ocean is formed which evolves to an axisymmetric dome which is associated with the Tharsis rise. (bottom) Crustal structure after isostatic adjustment can be estimated from the lateral spreading model. A circum-Mars profile through Tharsis of crustal thickness. Vertcal scale is in kilometers. Light and dark grey represent crust and mantle, respectively. Variable crustal structure within Tharsis may be due to the merger of late stage magma ocean evolution with mantle dynamics which can lead to subsequent localized melting (c.f. Figures 6-8).

Figure 6: Model A Noachian evolution (Table 3). (left) Evolution of the temperature field for a slice along longitude lines of $68^{\circ} \mathrm{E}$ to $248^{\circ}$ E. (center) Global map of the crustal thickness evolution. (right, top) The total melting rate as a function of time. (right, bottom) Circum-Mars profiles of crustal thickness along longitudes $68^{\circ} \mathrm{E}$ to $248^{\circ} \mathrm{E}$. Light and dark grey represent crust and mantle, respectively.

Figure 7: As for Figure 6 except for Model B (Table 3).

Figure 8: As for Figure 6 except for Model C (Table 3). 
Figure 9: The melt volume production rate as a function of time for Models A, B, and C. During the middle to late Amazonian epoch, Model B exhibits transient episodes of melting while Model $\mathrm{C}$ produces an approximately constant rate of $0.1 \mathrm{~km}^{3} / \mathrm{yr}$ after $\sim 2 \mathrm{Gyr}$. The melting rate required to bury $10 \mathrm{~m}$ topography at the observed resurfacing rate (Hartmann and Neukum, 2001) is shown with a dashed line.

Figure 10: Mars Global Surveyor topography (top) and present-day topography for Models A, B, and C (bottom). 
Reese et al., Figure1.eps

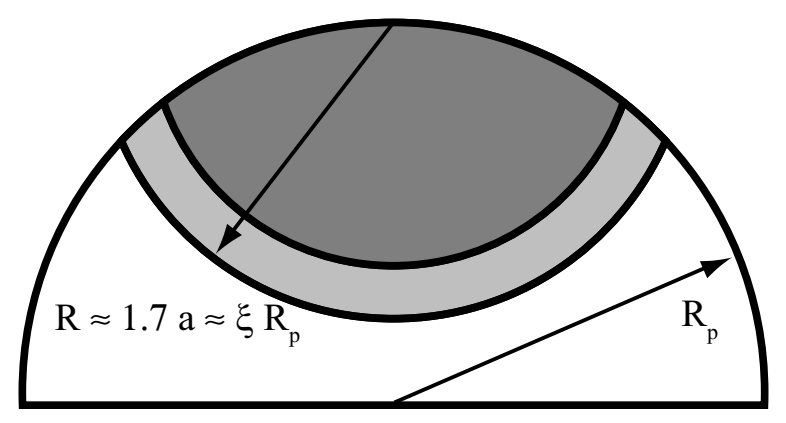


Reese et al., Figure2.eps
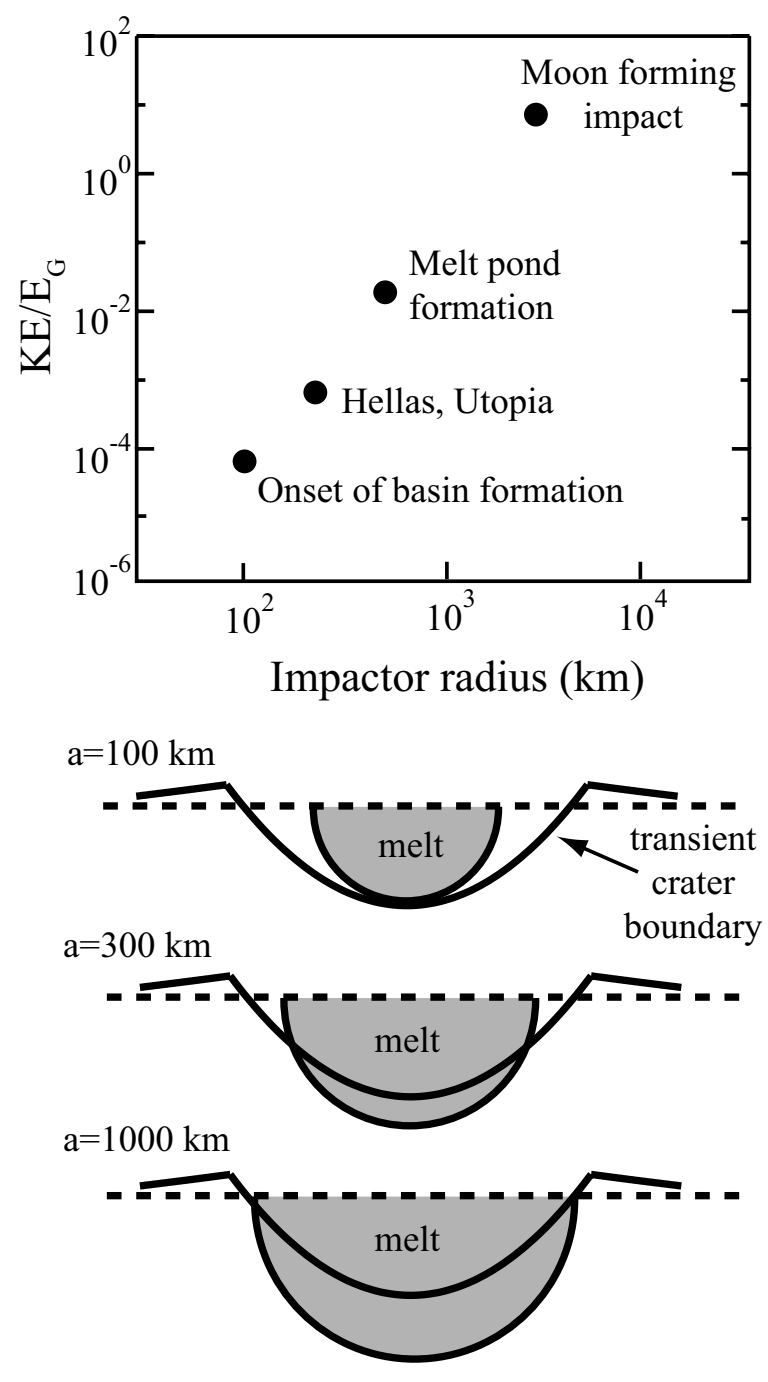
Reese et al., Figure3.eps

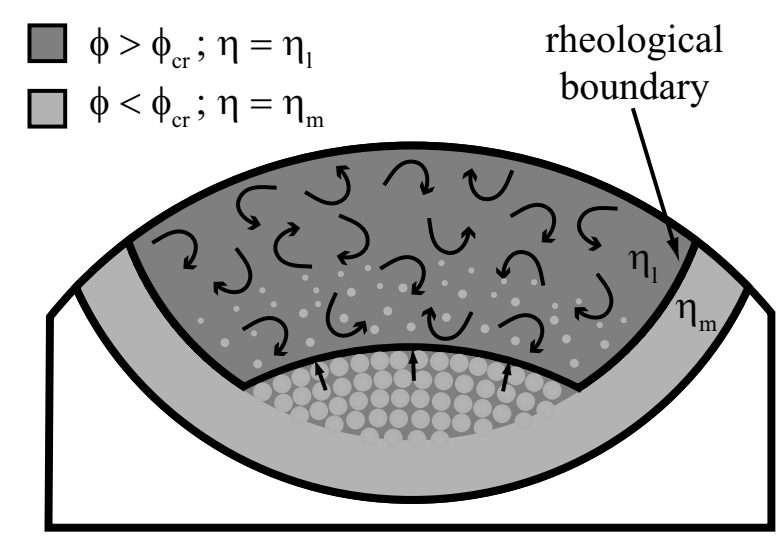


Reese et al., Figure4.eps

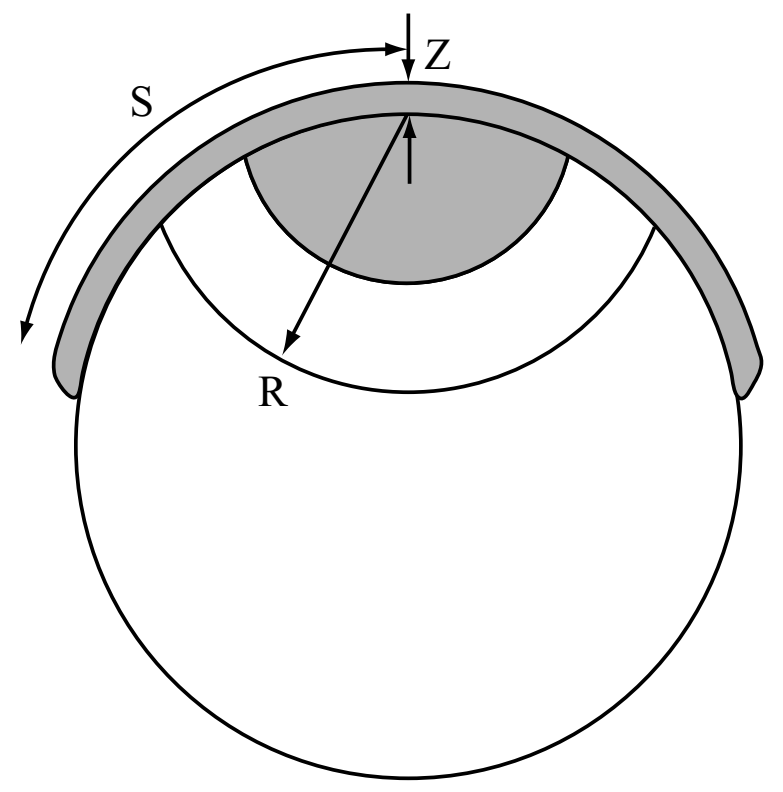


Reese et al., Figure5.eps
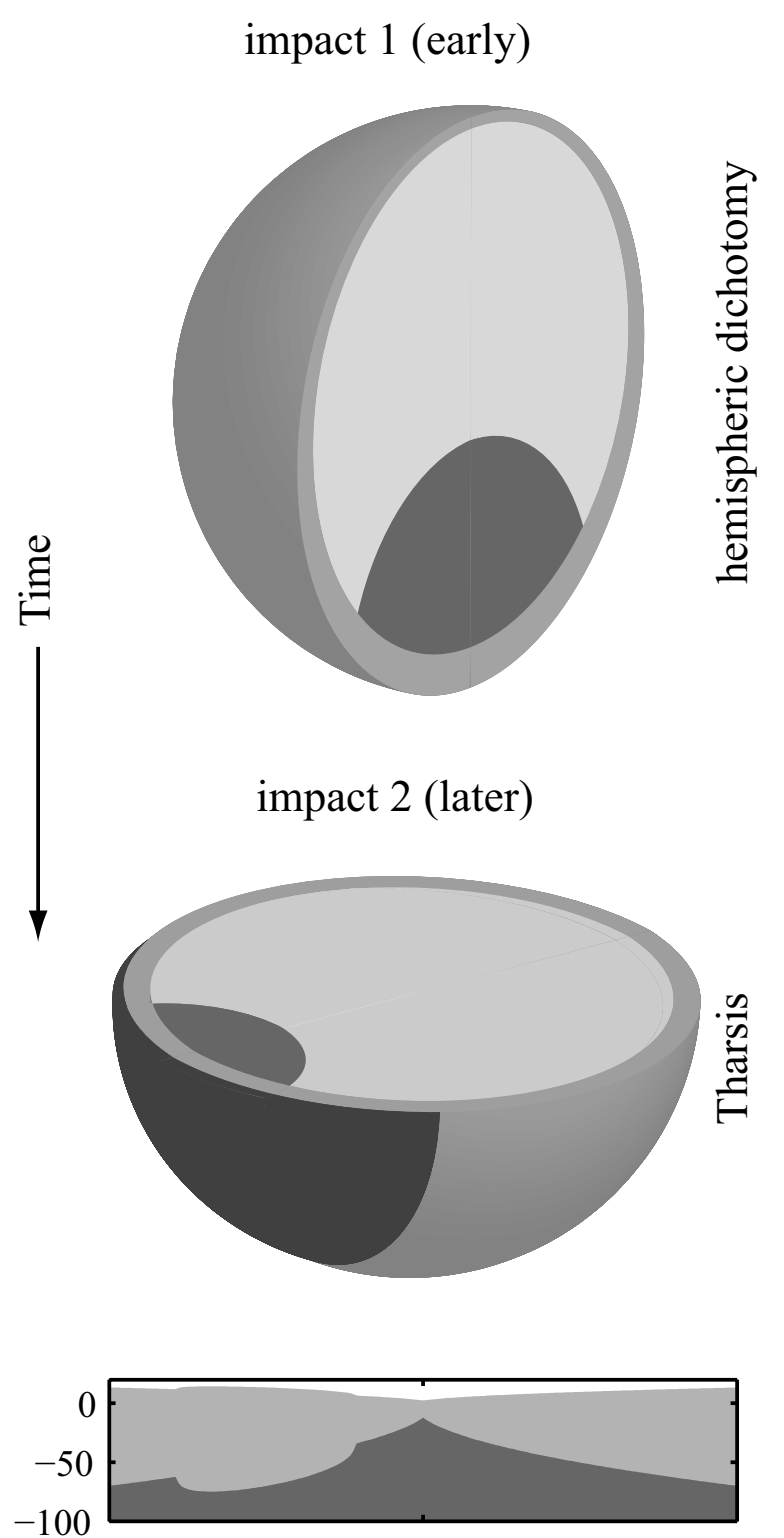
Reese et al., Figure6.eps

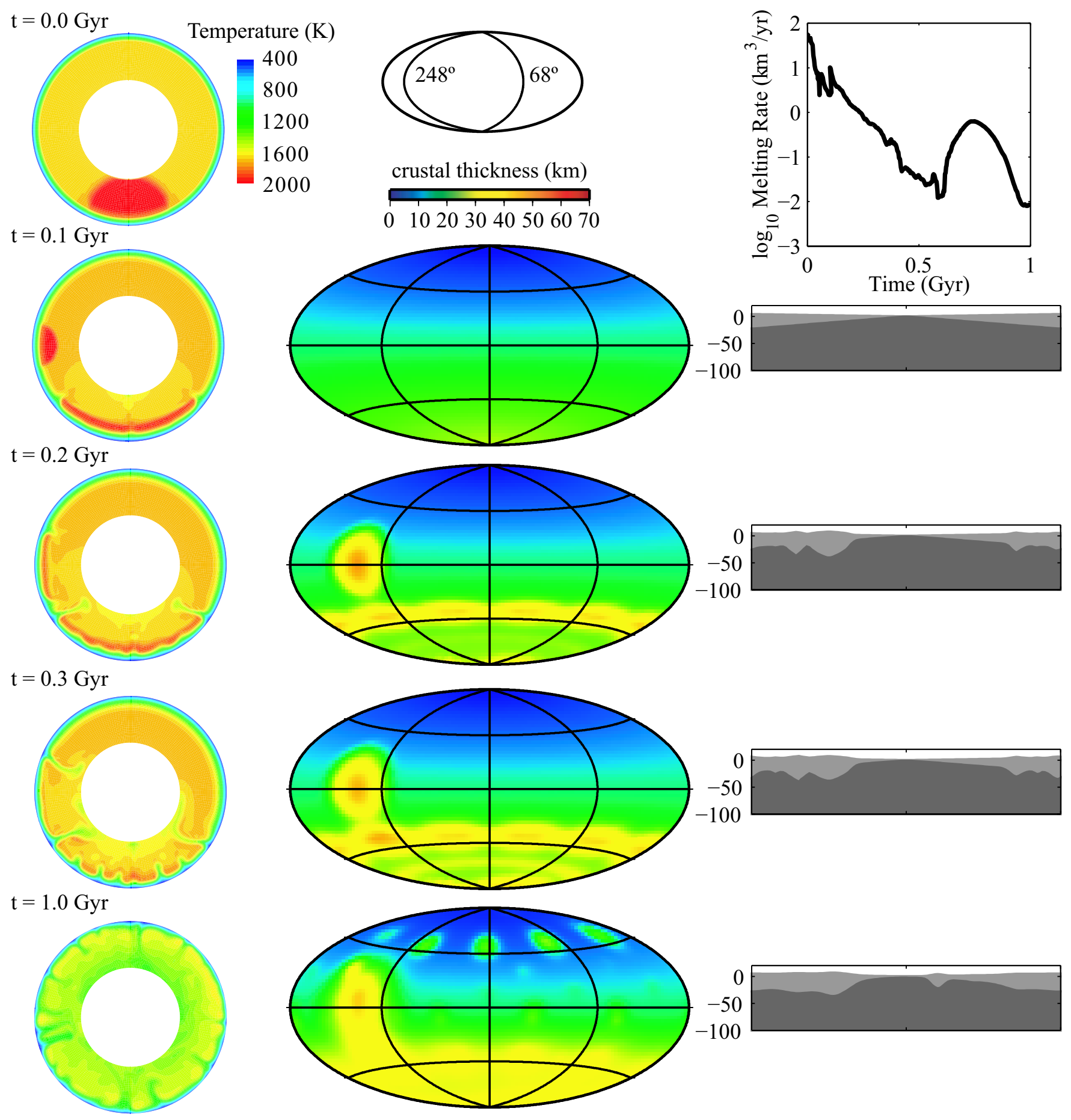


Reese et al., Figure7.eps




Reese et al., Figure8.eps

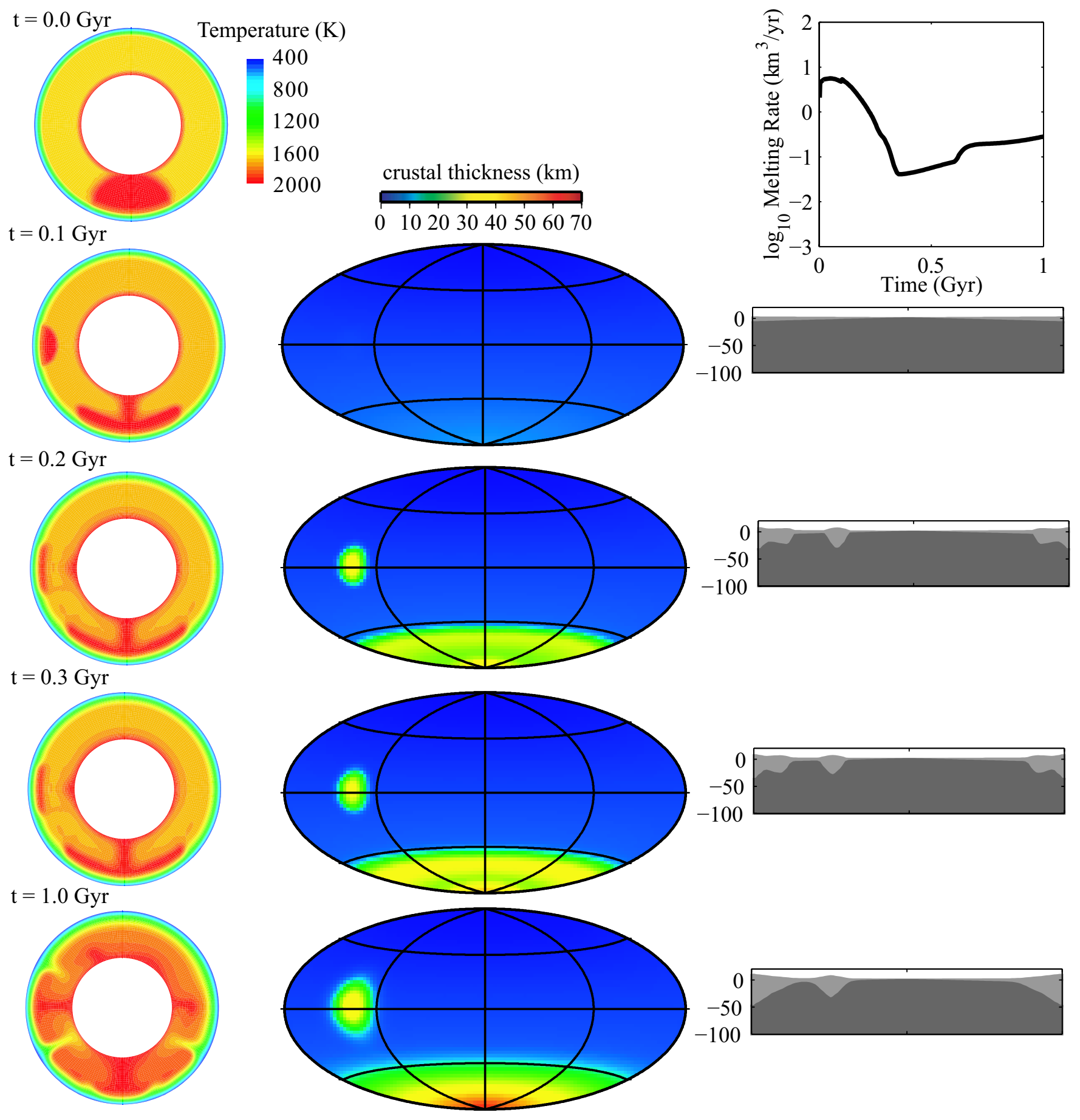


Reese et al., Figure9.eps

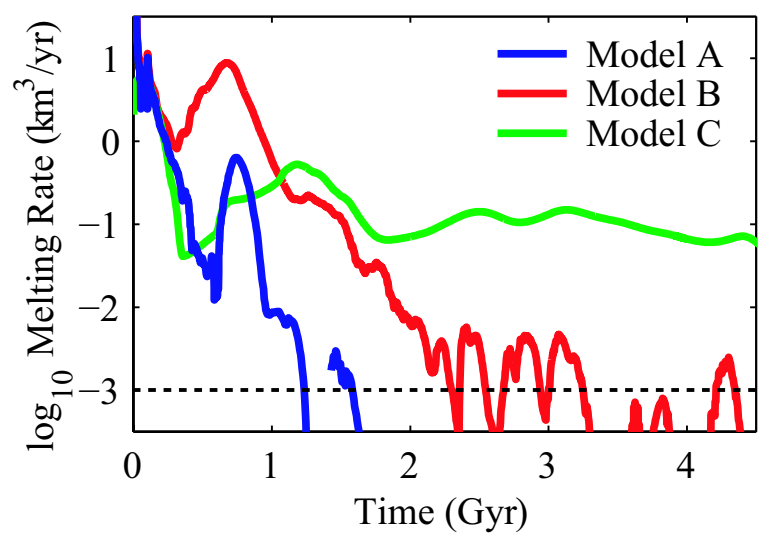


Reese et al., Figure10.eps
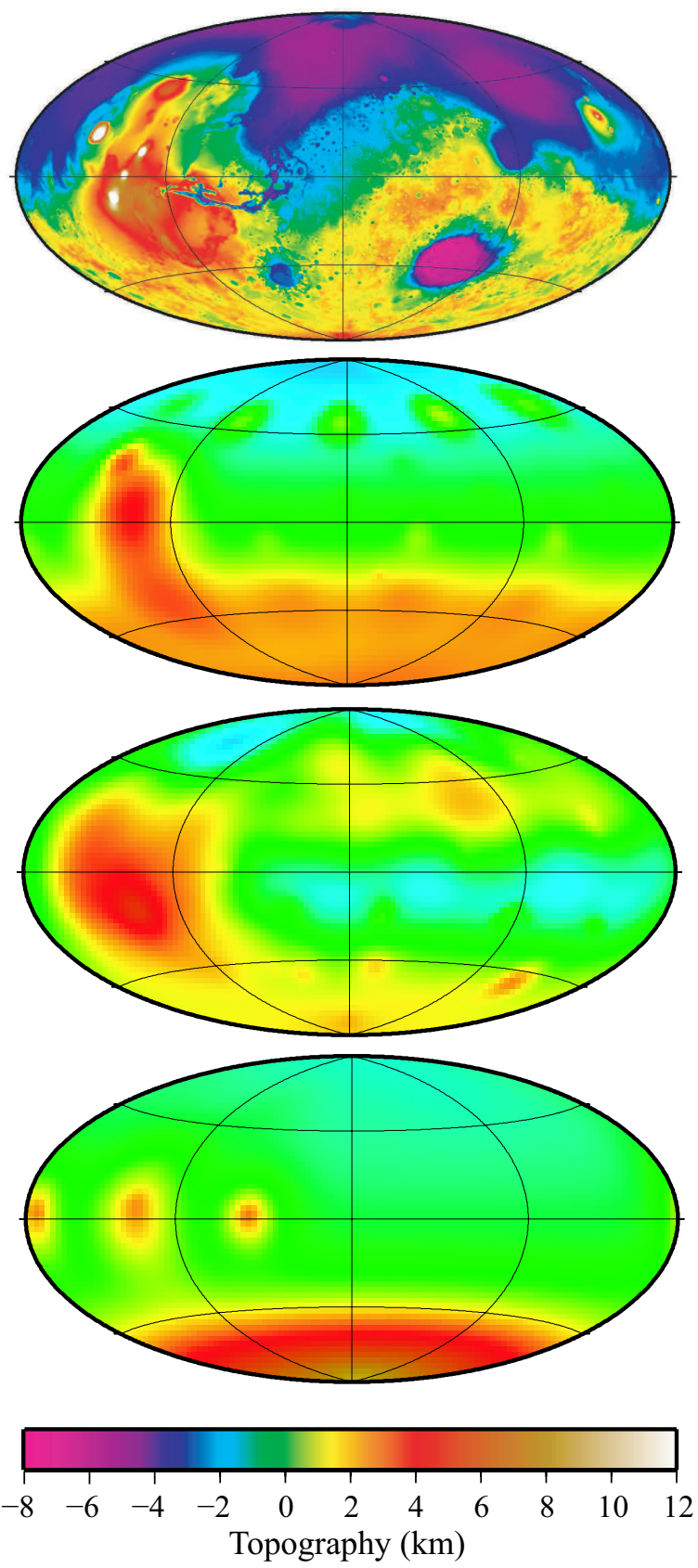